\title{
Determination of Total Phenolic Content and NIR-Chemometrics Classification Model of Queen and Local Varieties of Soursop (Annonamuricata L.) Leaf Powder
}

\author{
Lestyo Wulandari ${ }^{\star}$, Mellda Kusuma Candra Dewi, Nia Kristiningrum, and Raden Ajeng Yashinta \\ Nirmala Siswanti
}

Faculty of Pharmacy, University of Jember, Jl. Kalimantan 37, Jember 68121, East Java, Indonesia

\begin{abstract}
* Corresponding author:
Received: January 26, 2019

Accepted: August 9, 2019

DOI: $10.22146 / \mathrm{ijc} .43051$

\author{
email: lestyowulandari@unej.ac.id
}

Abstract: The leaves of soursop (Annonamuricata L.) are commonly used for health because of their antioxidant activity from its highest phytochemical content, namely phenolic compound, which is influenced by the varieties of this plant. In Indonesia, there are two soursop varieties, namely 'queen' and 'local' varieties which are difficult to determine morphologically. The aim of this study was to determine the total phenolic content of soursop leaves of both varieties and to establish a classification model of NIR spectroscopy combined with chemometrics for the identification of the varieties of soursop leaves. After the soursop leaves were dried and grinded, they were then scanned to obtain the spectra of NIR spectroscopy. NIR spectras were combined with chemometrics to classify the varieties of the soursop. The classification models used were Linear Discriminant Analysis (LDA), Support Vector Machines (SVM) and Soft Independent Modelling of Class Analogies (SIMCA). Total phenolic content of the soursop leaves was determined by UV-Vis spectroscopy using Folin-Ciocalteau reagent and gallic acid as reference. The result showed that the local variety had higher total phenolic content than the queen variety. NIR spectroscopy combined with chemometrics was able to classify the varieties of soursop leaves with 100\% accuracy using LDA and SVM.
\end{abstract}

Keywords: Annonamuricata L.; phenolic total; NIR; chemometrics

\section{- INTRODUCTION}

Soursop plants are widely used for traditional medicine, especially the leaves [1]. A previous study reported that soursop leaves have antioxidant activity [2], which has a role in health related activities [3]. The highest phytochemical content in soursop leaves is phenolic compounds [4], which is considered as the major phytochemical responsible for the antioxidant activity [5], so it is necessary to determine the total phenolic content of the soursop leaves. Many factors influence phytochemical content, one of which is the plant varieties [6]. There are two varieties of soursop that grow in Indonesia, namely 'queen' and 'local' varieties. The queen variety has a sweet fruit flavor, while the local variety has a sour slightly sweet fruit flavor. Both of these varieties are easily identified from the taste of the fruit but are difficult to distinguish if compared morphologically.
The determination of the total phenolic content of two varieties of soursop leaves in this study was performed by UV-Vis spectroscopy with FolinCiocalteau reagents and gallic acid standard as reported by some researchers [7-9]. The purpose of determining the total phenolic content is to find out which variety has potentially more phenolic compound. After the variety of the soursop leaves which has potentially more phenolic source was known, then the classification model was determined. The classification model was needed to identify the soursop leaves varieties because it is difficult to identify morphologically. Determination of the classification model was performed by the NIR (Near Infra-Red) spectroscopy and chemometrics. NIR spectroscopy is an effective analysis technique because it is nondestructive, can analyze at high speed, does not cause pollution, uses simple sample preparations and do not require chemicals. However, the spectra data from 
NIR spectroscopy is very complicated and overlapping, so chemometrics was used to analyze the spectral data. NIR coupled with chemometrics was used as a rapid analysis method in many studies [10-13]. NIR coupled with chemometrics was also used as high-speed sex identification and sorting of living silkworm pupae [14]. The classification models obtained were validated then the chosen model was applied for the determination of soursop varieties in the real sample. This study used samples in powder form because the preparations commonly used in traditional medicine are powder. The selected and validated classification model was then used to identify the varieties of soursop leaves from the supply of raw materials used for traditional medicines.

\section{- EXPERIMENTAL SECTION}

\section{Materials}

The materials used in this study were leaves of the queen and local soursop (Annonamuricata L.) varieties taken from Jember Regency (6 local and 6 queen), Bondowoso (6 local and 6 queen), Malang (1 local), and Ngawi (1 local), East Java, Indonesia. Reagents were methanol, gallic acid standard (purity-100\%, SigmaAldrich), Folin-Ciocalteau reagent (Merck), and $\mathrm{Na}_{2} \mathrm{CO}_{3}$, methanol $98 \%$, and distilled water.

\section{Instrumentation}

The instruments used in this study were the Near Infra-Red Brimrose Luminar 3070 spectrophotometer (NIR Industry, France), Brimrose software (Brimrose Corp., USA), The Unscrambler X 10.2 software (CAMO, UK), UV-Vis Hitachi U-1800 spectrophotometer (Hitachi High-Technologies Corp., Japan), oven (Memmert, Germany), analytical balance (Sartorius, Germany), grinder, vials, desiccators, funnels, volumetric flasks, cuvettes, 100 mesh siever, and glassware.

\section{Procedure}

\section{Sampling and sample preparation}

The samples were divided into training sets and test sets. Training sets were used for making the model and test set samples were used as an independent sample for validating the model. The leaf of the samples used for training and test sets were obtained from Jember Regency (training set QJ1-QJ5 and LJ1-LJ5, test set Queen J sample, and test set Local B sample) and Bondowoso Regency (training set QB1-QB5 and LB1-LB5, test set Queen B sample, and test set Local B sample), while leaves from Malang Regency and Ngawi Regency were used as real samples for testing. The sampling was done based on the simple random sampling technique, it was picked randomly from the gardens belonging to residents in the area. Varieties were verified based on information from the taste of the fruit (sweet for queen varieties and sour for local varieties). The samples were sorted wetly, washed, drily sorted, and then dried. Dry leaves were mashed using a grinder until the powder was obtained, then the powder was sifted to obtain less than 100 mesh leaves powder. Determination of moisture content in the powdered sample was carried out using the gravimetric method. Moisture content determination was carried out by weighing empty vials without covering then as much as $1 \mathrm{~g}$ of soursop leaf powder was put in the vial and heated at $105^{\circ} \mathrm{C}$ for $1 \mathrm{~h}$ then cooled in a desiccator in a closed vial state. After cooling down, the powder was then weighed. Heating with the oven was repeated for $30 \mathrm{~min}$ until a constant weight was obtained. Samples were restricted to $<10 \%$ of the moisture content. The water content was calculated as followed, Moisture content $(\%)=\frac{\mathrm{A}-\mathrm{B}}{\mathrm{A}} \times 100 \%$

where A is the weight of the initial sample $(\mathrm{g})$ and $\mathrm{B}$ is the sample weight after drying by the oven (g) [18].

\section{Determination of total phenolic content using Folin- Ciocalteu reagents}

This determination method of total phenolic content was validated by the authors in a previous study [19], the results of the validation are as seen in Table 2. Preparation of sample solutions and standards were carried out. Twenty five milligrams of each soursop leaves powder samples were weighed (replication three times) and dissolved with $98 \%$ methanol in a $10.0 \mathrm{~mL}$ volumetric flask, and were then filtered. The gallic acid was weighed 20.4 and $25.1 \mathrm{mg}$, each dissolved with 25.0 $\mathrm{mL}$ of $98 \%$ methanol in the volumetric flask so that the concentration of the gallic acid solution obtained was at 816 and $1004 \mu \mathrm{g} / \mathrm{mL}$. Then the standard solution was 
further diluted from $816 \mu \mathrm{g} / \mathrm{mL}$ to $8.16,81.16,5.02,20.08$, 30.12 and $50.02 \mu \mathrm{g} / \mathrm{mL}, 1004 \mu \mathrm{g} / \mathrm{mL}$ to $5.02,20.08,30.12$, and $50.02 \mu \mathrm{g} / \mathrm{mL}$ by pipetting a certain amount of gallic acid standard solution in a measuring flask and then adding 98\% methanol.

Optimization of maximum wavelength and incubation time was carried out using standard gallic acid solution concentration of $81.16 \mu \mathrm{g} / \mathrm{mL}$ added with $500 \mu \mathrm{L}$ of Folin-Ciocalteu (1:10 v/v water) and $400 \mu \mathrm{L} \mathrm{Na}_{2} \mathrm{CO}_{3}$ $(7.5 \% \mathrm{w} / \mathrm{v}$ water). The mixture was then incubated at the incubation time, and the absorbance was measured at a wavelength of $400-800 \mathrm{~nm}$. Determination of total phenolic content was carried out by pipetting $100 \mu \mathrm{L}$ of each standard solution and the sample solution then added with $500 \mu \mathrm{L}$ of Folin-Ciocalteu (1:10 v/v water). Then the mixture was incubated for $6 \mathrm{~min}$, and then added with $400 \mu \mathrm{L} \mathrm{Na}_{2} \mathrm{CO}_{3}$ (7.5\% w/v water) [15-16]. The mixture was then allowed to stand at room temperature during the incubation time, and later the absorbance was measured at the optimum wavelength.

\section{Spectra acquisition by NIR spectrophotometer}

The sample was placed on the sample plate until it was fully filled and the surface was flat (parallel to the surface of the plate), then it was placed on the sample site and the spectra was measured using a NIR spectrophotometer. The sample was scanned 5 times at whole wavelengths $(850-2000 \mathrm{~nm})$ and specific wavelengths. Each of the acquisition of the scan was carried out 3 times.

\section{Determination of the classification model and real sample application}

The spectra data produced by the NIR spectrophotometer were then analyzed by chemometrics using the Unscrambler $\mathrm{X}$ version 10.2 software. The classification model used was a Linear Discriminant Analysis (LDA), Support Vector Machines (SVM) and Soft Independent Modelling of Class Analogies (SIMCA). The results obtained from the chemometric analysis evaluated the ability of the model to distinguish simulation samples into actual categories using \% accuracy. The selected model was then validated using two cross-validation techniques, the first technique was Leave-One-Out-Cross-Validation (LOOCV) by taking 1 data set LB1, QB1, LJ1, RJ1 alternately and using the remaining 19 datasets as training sets. The second validation was 2-Fold-Cross-Validation (2FCV) which was performed by using 4 (four) independent samples as test set samples. The ideal model has accuracy value of $100 \%$. After validated, the classification model was used to identify the varieties of real samples. The real samples used were local varieties of soursop leaves from Malang and Ngawi Regency.

\section{- RESULTS AND DISCUSSION}

\section{Preparation and Determining Moisture Content (MC) of Leaves Powder}

The grounded powder was sieved in order to ensure uniformed particle size of the powder. This is because particle size can affect the length of light transmission that passes through the sample and affects the reflectance of the NIR spectra [17]. Well-controlled particle size and uniformity of samples are the basis for the formation of a good chemometric model [18]. In this study, 100 mesh was chosen to ensure particle size did not affect the spectra intensity produced. Powder samples sieved with 100 mesh (has particles sized $\leq 149 \mu \mathrm{m}$ ) resulted in spectra that were not affected by particle size [19]. The results of moisture content determination of queen and local varieties of soursop leaves powder were in the range of $3-5 \%$ as seen in Table 1.

Table 1 shows that the moisture content of soursop leaves powder was $\leq 10 \%$. This result fulfilled the requirements of the moisture content for traditional medicine products in Indonesia. Moisture content greater than $10 \%$ will cause damage by microbes. Another purpose of determining moisture content was to ensure there is no effect on the calculation results of the determination of the total phenolic content and classification model. The spectral reflectance of samples with moisture content more than $10 \%$ and less than $10 \%$ can be seen in Fig. 1. A researcher has reported that the higher the moisture content, the higher the absorption and the reflectance gets smaller. This is because water consists of hydrogen bonds by hydrogen atoms which are the most powerful atoms absorbing NIR waves [20]. In conclusion, the moisture content was determined in 


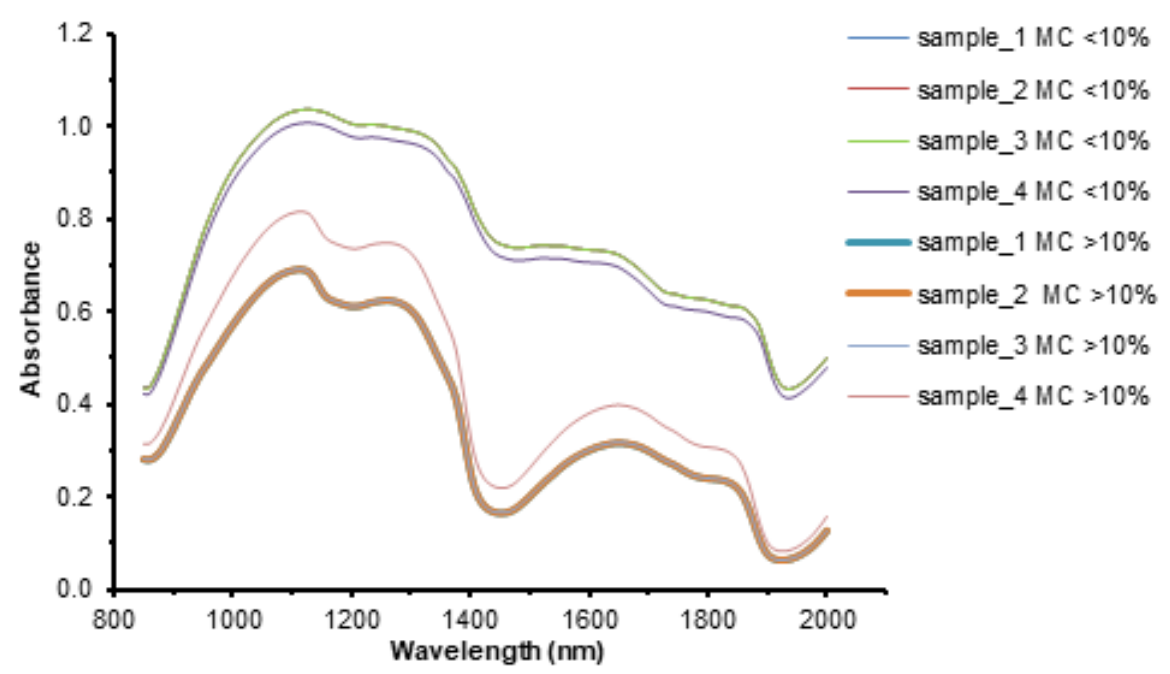

Fig 1. Spectra of samples wet powder with MC $>10 \%$ and dry powder with $\mathrm{MC}<10 \%$

Table 1. The results of sample moisture content

\begin{tabular}{cc}
\hline Code of sample & Water content $\pm \%$ RSD $(\mathrm{n}=3)$ \\
\hline QB1 & $3.53 \% \pm 1.72$ \\
QB2 & $4.07 \% \pm 0.74$ \\
QB3 & $4.31 \% \pm 1.68$ \\
QB4 & $3.85 \% \pm 0.83$ \\
QB5 & $3.71 \% \pm 2.30$ \\
QJ1 & $3.95 \% \pm 2.59$ \\
QJ2 & $3.38 \% \pm 2.14$ \\
QJ3 & $3.77 \% \pm 2.62$ \\
QJ4 & $3.76 \% \pm 2.93$ \\
QJ5 & $3.85 \% \pm 2.34$ \\
LB1 & $4.75 \% \pm 2.23$ \\
LB2 & $4.51 \% \pm 1.26$ \\
LB3 & $4.35 \% \pm 1.76$ \\
LB4 & $4.02 \% \pm 1.74$ \\
LB5 & $4.59 \% \pm 1.10$ \\
LJ1 & $4.86 \% \pm 1.54$ \\
LJ2 & $3.89 \% \pm 1.12$ \\
LJ3 & $4.84 \% \pm 1.76$ \\
LJ4 & $4.60 \% \pm 0.98$ \\
LJ5 & $4.66 \% \pm 2.36$ \\
Test set Queen B & $4.52 \% \pm 1.84$ \\
Test set Queen J & $3.64 \% \pm 2.34$ \\
Test set Local B & $4.48 \% \pm 2.17$ \\
Test set Local J & $4.76 \% \pm 2.61$ \\
\hline & \\
\hline
\end{tabular}

the sample to ensure the resulting spectra were not affected by moisture content.

\section{Determination of Total Phenolic Content with Addition of Folin-Ciocalteu Reagents}

In this study, gallic acid standards were chosen because it is one of the types of phenolic compound found
Table 2. The results of validation of the UV-Vis spectroscopy method for determination of total phenolic content

\begin{tabular}{ll}
\hline \multicolumn{1}{c}{ Parameter of Validation } & \multicolumn{1}{c}{ Result } \\
\hline Linearity & \\
Linearity range $(\mathrm{n}=6)$ & $4.08-12.24 \mathrm{ppm}$ \\
Correlation coefficient & 0.9943 \\
Relative process standard deviation (Vxo) & $4.91 \%$ \\
DL & $1.13 \mathrm{ppm}$ \\
QL & $3.75 \mathrm{ppm}$ \\
Precision (RSD, $\mathrm{n}=3)$ & $0.73 \%$ \\
Accuracy (Recovery, mean $\pm \% \mathrm{RSD})$ & \\
$30 \%$ addition & $99.807 \pm 1.5$ \\
$60 \%$ addition & $98.142 \pm 1.0$ \\
\hline
\end{tabular}

in soursop leaves [5]. Gallic acid was a recommended reference for the determination of total phenolic using Folin-Ciocalteau reagents [21]. Determination of total phenolic content by UV-Vis spectroscopy using FolinCiocalteau (FC) reagents was chosen because it is relatively fast, simple, reliable, and more accurate than other methods such as permanganate oxidation [22-23]. The principle reaction of this method is the reduction of Molybdate (VI) reaction on FC reagents by phenolic ions in the sample to form complex blue compounds that can be measured by UV-Vis spectrophotometer. The UV-Vis spectroscopy method for the determination of total phenolic content in this study was validated. The results of the assessment of validation parameters listed in Table 2 showed that the UV-Vis spectroscopy method 
for the determination of total phenolic content was linear, precise, and accurate. $765 \mathrm{~nm}$ was chosen as the optimum wavelength because it had the maximum absorbance. In general, when the absorbance is to be measured at a single wavelength, the wavelength with the maximum absorbance is chosen [24]. Based on the research reported by Prior, it was shown that to provide reliable results on the supply of total phenolics with Folin-Ciocalteu reagents, it was recommended to use a wavelength of $765 \mathrm{~nm}$.

The optimum incubation time is the time needed to obtain a steady state absorbance response. The result of the optimization of incubation time for the gallic acid solution, sample solutions of the queen variety) and sample solutions of the local variety were 40,55 and 80 min, respectively. The longest incubation time $(80 \mathrm{~min})$ was applied for all sample solution. This study used six concentrations of standard solutions where the regression of the gallic acid standard curve was $y=0.0877 x+0.0669$ and $r=0.9983$. Determination of total phenolic content of soursop leaves powder of queen and local varieties was carried out by measuring the absorbance of each sample solution and then calculating the concentrations with the standard gallic acid curve. Table 3 and Fig. 2 show the results of the total phenolic content in the samples obtained.

In Table 3 and Fig. 2, the phenolic content of soursop leaves powder clearly showed that the local variety had higher phenolic content than the queen variety at all planting areas. The results obtained showed that the soursop leaves powder of the local variety had more potential phenolic content, where the mean of the total phenolic content for the local variety and the queen variety was $38.478 \mathrm{mg} \mathrm{GAE} / \mathrm{g}$ and $10.401 \mathrm{mg} \mathrm{GAE} / \mathrm{g}$, respectively. In this study, the results of the total phenolic content were varied among samples of the same variety. This is probably due to other factors that affect the total phenolic content of the sample, such as altitude, considering that samples of each varieties were taken in areas with different altitudes. For the local variety samples, LB2 that was taken from the highest location (792 masl) had the highest total phenolic content $(54.583 \mathrm{mg} / \mathrm{g})$. Meanwhile, for the queen variety, the highest phenolic content was QB3 which had phenolic content of $21.741 \mathrm{mg} \mathrm{GAE} / \mathrm{g}$ that was obtained

Table 3. The results of determining the total phenolic content of the sample

\begin{tabular}{lcc}
\hline Code of Sample & mg GAE/g powder \pm RSD $(\mathrm{n}=3)$ & Altitude (masl) \\
\hline QJ1 & $12.08 \pm 1.87$ & 113 \\
QJ2 & $5.15 \pm 2.44$ & 19 \\
QJ3 & $10.75 \pm 2.45$ & 19 \\
QJ4 & $9.95 \pm 0.95$ & 19 \\
QJ5 & $4.89 \pm 2.12$ & 54 \\
QB1 & $5.20 \pm 2.33$ & 241 \\
QB2 & $17.5 \pm 1.34$ & 241 \\
QB3 & $21.7 \pm 1.64$ & 269 \\
QB4 & $9.50 \pm 1.67$ & 199 \\
QB5 & $7.28 \pm 2.30$ & 199 \\
\hline LJ1 & $37.4 \pm 0.63$ & 99 \\
LJ2 & $43.3 \pm 0.79$ & 433 \\
LJ3 & $52.6 \pm 1.59$ & 433 \\
LJ4 & $34.1 \pm 0.73$ & 433 \\
LJ5 & $43.5 \pm 2.67$ & 433 \\
LB1 & $32.3 \pm 0.12$ & 792 \\
LB2 & $54.6 \pm 2.68$ & 792 \\
LB3 & $30.9 \pm 2.15$ & 313 \\
LB4 & $33.0 \pm 1.19$ & 313 \\
LB5 & $23.0 \pm 1.57$ & 295 \\
\hline
\end{tabular}




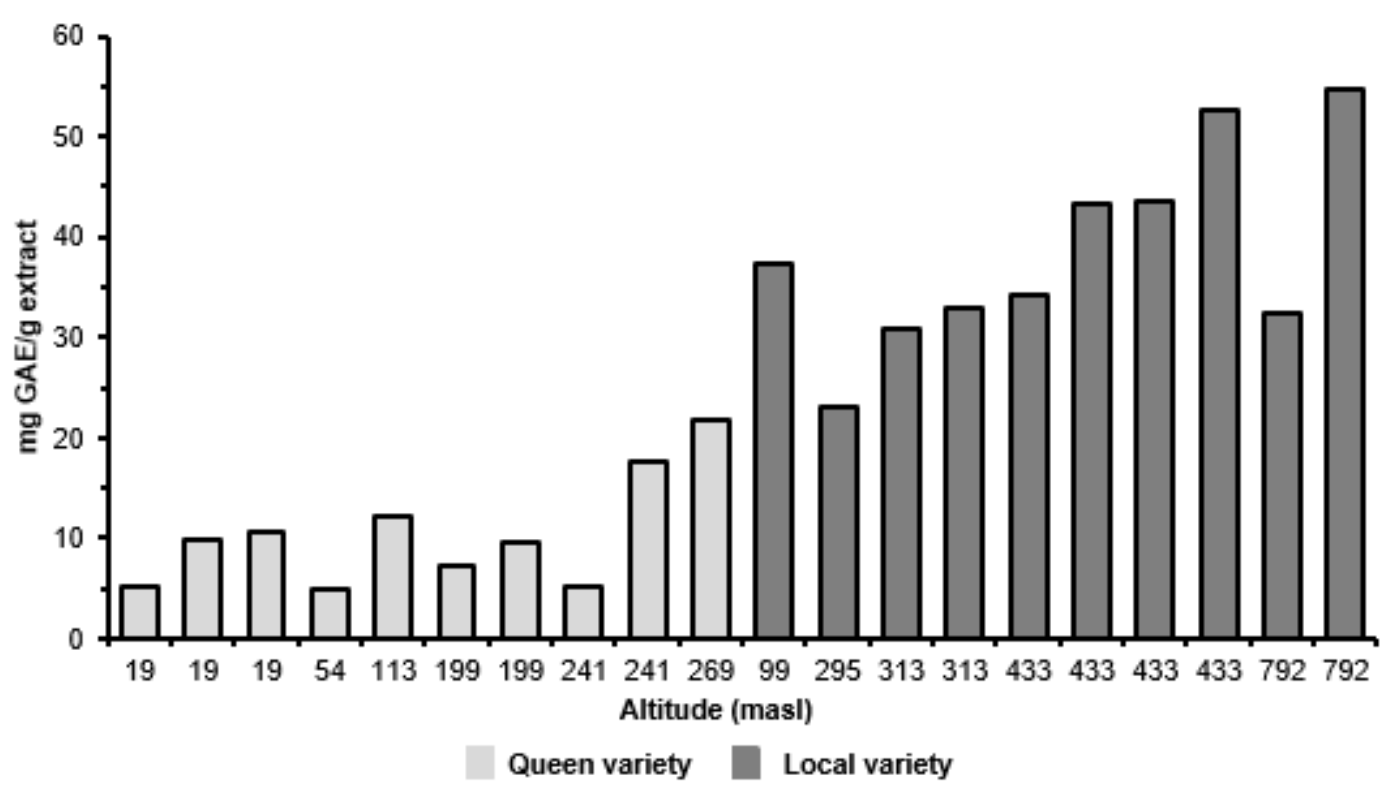

Fig 2. Total phenolic content of queen and local varieties at all plantation area

from a sample taken from an altitude of 269 masl. The higher the place, the higher the stress of the environment, for example, the lower the temperature, the higher the humidity, the lower the intensity of sunlight, and the shorter the duration of irradiation. The stress of temperature, light, humidity, etc. can affect the production of plant secondary metabolites. When experiencing stress, the production of secondary metabolites increases. This is an attempt of plants to fight environmental stress. However, QB5 had total phenolic content lower than QJ1, even though QB5 was obtained from a place which had a higher altitude than QJ1. In addition, samples with the same variety and altitude also resulted in variations of the total phenolic content in LB1 and LB2 samples. This might have occurred because of other factors, namely the nutrients available because macro soil nutrients such as Nitrogen (N), Potassium (K), Organic Ingredients and Carbon $(\mathrm{C})$ organically have a linear relationship with the formation of secondary metabolites [25].

\section{Determination of the Classification Model}

Determination of the classification model was performed by scanning the spectra data from each training set. The training set spectras were used to form the chemometric classification model namely LDA, SVM, and SIMCA. Basically, LDA, SVM, and SIMCA have the same working principle as supervised pattern recognition which has better classification results than unsupervised pattern recognition. Supervised pattern recognition analysts have control over the classification of samples, which means the sample's category is determined previously by the analysts which are referred to as training sets in order to facilitate the process of determining the classification [26]. The three models were used to classify two types of categories, namely the queen and local categories. This category intended to classify samples based on their varieties. The results of the chart mapping of the LDA and SVM classification models are shown in Fig. 3. The accuracy of predictive ability of the LDA, SVM, and SIMCA classification models can be seen in Table 4 .

The ability of the classification model can be seen from the percent accuracy of the mapping results of the LDA, SVM, and SIMCA models. Accuracy values showed the ability of the model to grouping simulation of the samples into two categories, namely queen and local. The accuracy of the LDA and SVM models were $100 \%$ while the SIMCA model was only $93.33 \%$. The SIMCA model with percent accuracy of $93.33 \%$ showed that the SIMCA model that was created based on the PCA model from the training set was not able to group all samples in the correct category. This is because the SIMCA classification model was based on the PCA model. 
Table 4. The predictive ability of LDA, SVM, and SIMCA

\begin{tabular}{lccc}
\hline \multirow{2}{*}{ Model } & \multicolumn{2}{c}{ Predictive ability (\% Accuracy) } \\
\cline { 2 - 4 } & At whole NIR & \multicolumn{2}{c}{ At specific wavelength } \\
\cline { 2 - 4 } & wavelength $850-2000 \mathrm{~nm}$ & $850-1100 \mathrm{~nm}$ & $1600-1650 \mathrm{~nm}$ \\
\hline SVA & $100 \%$ & $91.67 \%$ & $52.67 \%$ \\
SIMCA & $100 \%$ & $92.0 \%$ & $54.33 \%$ \\
\hline
\end{tabular}

(a)

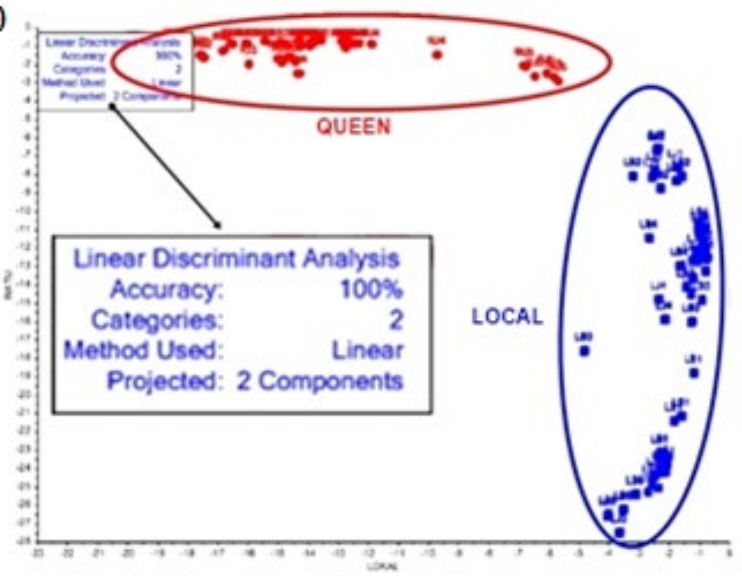

(b)

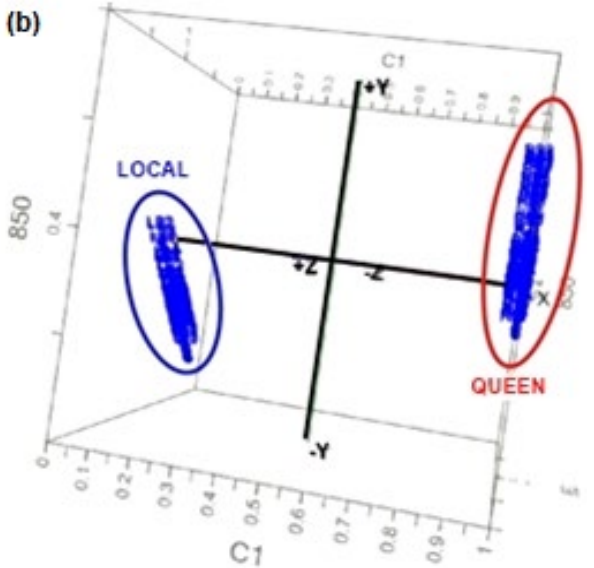

Fig 3. The mapping chart of classification models (a) LDA, (b) SVM

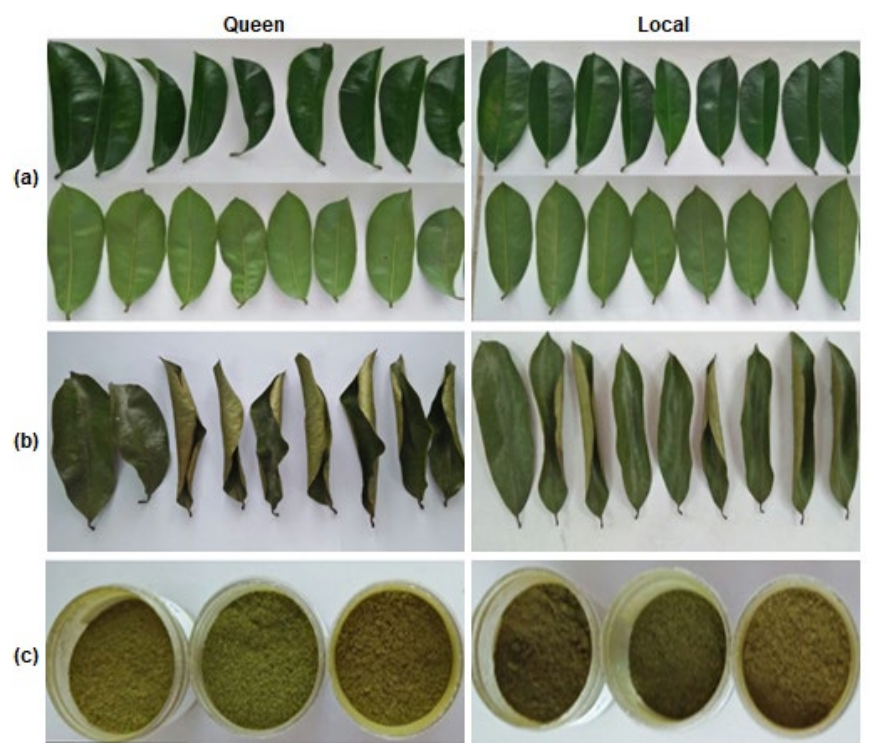

Fig 4. Queen and local soursop leaves (a) on wet, (b) dry, and (c) powder form

The PCA model has a disadvantage in being less optimal in the separation between classes so that the accuracy obtained was less than $100 \%$. The $100 \%$ accuracy of the LDA and SVM models showed that the model was able to classify soursop leaves powder in correct varieties with the prediction accuracy of $100 \%$. In this research, the classification models were also carried out at specific wavelengths which have functional groups characteristic of phenol compounds, namely $\mathrm{Ar}-\mathrm{OH}$ and $\mathrm{O}-\mathrm{H}$. However, at these wavelengths, the classification model did not produce $100 \%$ accuracy. The accuracy of the LDA and SVM models at specific wavelengths can be seen in Table 4. Both varieties of soursop leaves were difficult to identify on wet and dry leaves, and also in powder form (Fig. 4), so the LDA and SVM classification model can help the identification of the two varieties of soursop leaves. The model's ability to recognize the identity of varieties of the plant can be used to control the quality of raw materials of traditional medicines that utilizes soursop leaves.

\section{Validation of the Selected Classification Model}

Cross-validation is a technique for assessing how far a statistical analysis result can be implemented into an independent data set. Cross-validation is used to estimate how accurate the prediction model is and how it is to be implemented. After $100 \%$ accuracy of prediction was 
Table 5. The results of the model application in the real sample

\begin{tabular}{|c|c|c|c|c|c|c|}
\hline \multirow{3}{*}{ Sample Codename } & \multicolumn{4}{|c|}{ The Results of the Category Prediction by the Model (data) } & \multirow{2}{*}{\multicolumn{2}{|c|}{$\begin{array}{c}\text { Theoretical Category } \\
\text { (data) }\end{array}$}} \\
\hline & \multicolumn{2}{|c|}{ LDA } & \multicolumn{2}{|c|}{ SVM } & & \\
\hline & Queen & Local $^{\star}$ & Queen & Local $^{*}$ & Queen & Local \\
\hline Local Malang & 0 & 15 & 0 & 15 & 0 & 15 \\
\hline Local Ngawi & 0 & 15 & 0 & 15 & 0 & 15 \\
\hline
\end{tabular}

${ }^{*}$ number of scanned spectra data

obtained, LDA and SVM models were then validated by cross validation. In this study, the validations were LeaveOne-Out-Cross Validation and 2-Fold-Cross-Validation, because it has been proven effective for validating the classification chemometric model in previous studies $[15,22]$. The results of Leave-One-Out-Cross Validation obtained in this study were $100 \%$ accurate. This means there was no sample classified in the wrong variety. The 2 -fold cross-validation in this study used 4 sample test sets in which their category were already known. The results of 2-fold cross-validation showed there was no sample grouped in the wrong category $(100 \%$ accurate prediction).

\section{Application on Real Samples}

The real sample used was soursop leaves powder of the local variety originating from Malang and Ngawi Regencies. Samples were chosen from outside Jember and Bondowoso Regencies to ensure that the models could be used for determination of the plant varieties of soursop leaves from other planting areas, not only from Jember and Bondowoso Regencies. There were no samples collected from the market because the samples in the market were not attached with information on the raw material of the soursop leaves varieties. The classification model was able to predict correctly all varieties of the soursop leaves powder samples from Malang and Ngawi Regencies (100\% correct prediction). The results of the model application in the real samples can be seen in Table 5 , in which all spectra data of each real sample was categorized as the local variety.

\section{- CONCLUSION}

The local variety of the soursop leaves has more potential as a source of total phenolic compound with an average content of $38.478 \mathrm{mg} \mathrm{GAE} / \mathrm{g}$, while the queen variety has an average content of $10.401 \mathrm{mg}$ GAE/g. NIR and chemometric methods (LDA and SVM) can be used to classify queen and local varieties of soursop leaves powder.

\section{- ACKNOWLEDGMENTS}

The authors are grateful to the Research Group of Pharmaceutical Analysis and Chemometrics, Faculty of Pharmacy, University of Jember.

\section{- REFERENCES}

[1] Muizuddin, M., and Zubaidah, E., 2015, Studi aktivitas antibakteri kefir teh daun sirsak (Annona muricata Linn.) dari berbagai merk teh daun sirsak di pasaran, Jurnal Pangan dan Agroindustri, 3 (4), 1662-1672.

[2] Justino, A.B., Miranda, N.C., Franco, R.R., Martins, M.M., DaSilva, N.M., and Espindola, F.S., 2018, Annona muricata Linn. leaf as a source of antioxidant compounds with in vitro antidiabetic and inhibitory potential against $\alpha$-amylase, $\alpha$ glucosidase, lipase, non-enzymatic glycation and lipid peroxidation, Biomed. Pharmacother., 100, 83-92.

[3] Roduan, M.R.M., Hamid, R.A., Sulaiman, H., and Mohtarrudin, N., 2017, Annona muricata leaves extracts prevent DMBA/TPA-induced skin tumorigenesis via modulating antioxidants enzymes system in ICR mice, Biomed. Pharmacother., 94, 481-488.

[4] Minari, J.B., and Okeke, U., 2014, Chemopreventive effect of Annona muricata on DMBA-induced cell proliferation in the breast tissues of female albino mice, Egypt. J. Med. Hum. Genet., 15 (4), 327-334.

[5] Coria-Téllez, A.V., Montalvo-Gónzalez, E., Yahia, E.M., and Obledo-Vázquez, E.N., 2018, Annona 
muricata: A comprehensive review on its traditional medicinal uses, phytochemicals, pharmacological activities, mechanisms of action and toxicity, Arabian J. Chem., 11 (5), 662-691.

[6] Chang, X., Ye, Y., Pan, J., Lin, Z., Qiu, J., Guo, X., and Lu, Y., 2018, Comparative assessment of phytochemical profiles and antioxidant activities in selected five varieties of wampee (Clausena lansium) fruits, Int. J. Food Sci. Technol., 53 (12), 2680-2686.

[7] Toledo-Martín, E.M., Font, R., Obregón-Cano, S., De Haro-Bailón, A., Villatoro-Pulido, M., and Del RíoCelestino, M., 2017, Rapid and cost-effective quantification of glucosinolates and total phenolic content in rocket leaves by visible/near-infrared spectroscopy, Molecules, 22 (5), 851.

[8] Aleixandre-Tudo, J.L., and du Toit, W., 2019, “The role of UV-Visible spectroscopy for phenolic compounds quantification in winemaking" in Frontiers and New Trends in the Science of Fermented Food and Beverages, Eds. Solis-Oviedo, R.L., IntechOpen, London.

[9] Sasikala, S., and Radhaisri, S., 2017, Analysis of total phenol in developed nutraceutical by UV-VIS spectrophotometry, Int. J. Sci. Res., 6 (11), 513-517.

[10] Jimenez, R., Molina, L., Zarei, I., Lapis, J.R., Chavez, R., Cuevas, R.P.O., and Sreenivasulu, N., 2019, Method development of near-infrared spectroscopy approaches for nondestructive and rapid estimation of total protein in brown rice flour, Methods Mol. Biol., 1892, 109-135.

[11] Su, W.H., Bakalis, S., and Sun, D.W., 2019, Chemometrics in tandem with near infrared (NIR) hyperspectral imaging and Fourier transform mid infrared (FT-MIR) microspectroscopy for variety identification and cooking loss determination of sweet potato, Biosyst. Eng., 180, 70-86.

[12] Ferreiro-González, M., Espada-Bellido, E., GuillénCueto, L., Palma, M., Barroso, C.G., and Barbero, G.F., 2018, Rapid quantification of honey adulteration by visible-near infrared spectroscopy combined with chemometrics, Talanta, 188, 288292.
[13] Kutsanedzie, F.Y.H., Chen, Q., Hassan, M.M., Yang, M., Sun, H., and Rahman, M.H., 2018, Near infrared system coupled chemometric algorithms for enumeration of total fungi count in cocoa beans neat solution, Food Chem., 240, 231-238.

[14] Zhu, Z., Yuan, H., Song, C., Li, X., Fang, D., Guo, Z., Zhu, X., Liu, W., and Yan, G., 2018, High-speed sex identification and sorting of living silkworm pupae using near-infrared spectroscopy combined with chemometrics, Sens. Actuators, B, 268, 299309.

[15] Wulandari, L., Siswanti, R.A.Y.N., and Nugraha, A.S., 2019, Determination of total phenolic content and classification model of local variety soursop (Annona muricata L.) leaf powder in different altitudes using NIR and FTIR spectroscopy coupled with chemometrics, Indones. J. Pharm., 30 (1), 714.

[16] Keskin-Šašić, I., Tahirović, I., Topčagić, A., Klepo, L., Salihović, M., Ibragić, S., Toromanović, J., Ajanović, A., and Velispahić, E., 2012, Total phenolic content and antioxidant capacity of fruit juices, Glas. Hem. Tehnol. Bosne Herceg., 39, 25-28.

[17] Chang, C.W., Laird, D., Mausbach, M.J., and Hurburgh, C.R., 2001, Near-infrared reflectance spectroscopy principal component regression analyses of soil properties, Soil Sci. Soc. Am. J., 65 (2), 480-490.

[18] Zhu, Z., Chen, S., Wu, X., Xing, C., and Yuan, J., 2018, Determination of soybean routine quality parameters using near-infrared spectroscopy, Food Sci. Nutr., 6 (4), 1109-1118.

[19] Yang, J., Liu, Z., Liu, B., and Zhu, Q., 2012, Determination of Coptis chinensis' quality by FTNIR spectroscopy, Health, 4 (4), 196-202.

[20] Agustina, S., Purwanto, Y.A., and Budiastra, I.W., 2015, Prediksi kandungan kimia mangga arumanis selama penyimpanan dengan spektroskopi NIR, JTEP, 3 (1), 57-63.

[21] Wulandari, L., Nuri, Retnaningtyas, Y., and Lukman, H., 2016, Analysis of flavonoid in medicinal plant extract using infrared spectroscopy 
and chemometrics, J. Anal. Methods Chem., 2016, 4696803.

[22] Prior, R.L., Wu, X., and Schaich, K., 2005, Standardized methods for the determination of antioxidant capacity and phenolics in foods and dietary supplements, J. Agric. Food Chem., 53 (10), 4290-4302.

[23] Khoddami, A., Wilkes, M.A., and Robert, T.H., 2013, Techniques for analysis of plant phenolic compounds, Molecules, 18 (2), 2328-2375.

[24] Rouessac, F., and Rouessac, A., 2007, Chemical Analysis: Modern Instrumentation Methods and
Techniques, $2^{\text {nd }}$ Ed., John Wiley \& Sons Ltd, England.

[25] Salim, M., Yahya, Y., Sitorus, H., Ni'mah, T., and Marini, M., 2016, Hubungan kandungan hara tanah dengan produksi senyawa metabolit sekunder pada tanaman duku (Lansium domesticum Corr var Duku) dan potensinya sebagai larvasida, Jurnal Vektor Penyakit, 10 (1), 11-18.

[26] Enderle, D.I.M., and Weih, R.C., 2005, Integrating supervised and unsupervised classification methods to develop a more accurate land cover classification, J. Arkansas Acad. Sci., 59 (10), 65-73. 